Article

\title{
Thermal Viscous Fingering in Thermal Recovery Processes
}

\author{
Maureen Austin-Adigio and Ian D. Gates * \\ Department of Chemical and Petroleum Engineering, University of Calgary, Calgary, AB T2N 1N4, Canada; \\ maureendigio@gmail.com \\ * Correspondence: ian.gates@ucalgary.ca
}

Received: 25 May 2020; Accepted: 16 September 2020; Published: 22 September 2020

\begin{abstract}
Heat and fluid flow at the edge of steam chambers found in thermal recovery processes such as steam-assisted gravity drainage and cyclic steam stimulation remain unresolved. Given the multiple phases present and contrast of thermophysical properties, it remains unclear where instabilities occur within this thin, yet critical, zone of the process. In the research reported here, heat and fluid flow are examined in vertical and horizontal sections of a steam chamber to understand the differences between the two orientations by using detailed and fine-gridded thermal reservoir simulation models. The results show that heat transfer in vertical and horizontal directions are different with greater heat transfer found in the vertical orientation. In the vertical direction, heat transfer occurs with mobilized bitumen draining with subsequent steam moving into the emptied pore space. Conduction beyond the edge of the chamber dominates and heated, low viscosity bitumen fingers into cold, higher viscosity bitumen at the edge of the chamber. Relative permeability effects are observed which can interfere with enhanced oil mobility.
\end{abstract}

Keywords: thermal recovery; viscous fingering; steam chambers; oil sands; heat transfer

\section{Introduction}

Cyclic steam stimulation (CSS) and steam-assisted gravity drainage (SAGD) are examples of commonly used thermal enhanced oil recovery methods for recovering heavy oil and bitumen (HO/B). These processes rely on the use of steam as an agent to transfer heat to the cold $\mathrm{HO} / \mathrm{B}$ thus raising its temperature. Once heated, say from 10 to $220^{\circ} \mathrm{C}$, the viscosity of the $\mathrm{HO} / \mathrm{B}$ is reduced by over five orders of magnitude and under the action of gravity, drains to a production well [1]. In SAGD and CSS, gravity drainage is induced as a result of the density difference between the injected steam, natural and generated gases and mobilized oil. The effective delivery of heat to cold bitumen and subsequent mobilization and drainage of oil requires an understanding of the dynamics that occurs as heat is transported through the system.

Our understanding of heat and mass transport in thermal recovery systems, such as SAGD, displayed schematically in Figure 1, is not well resolved. For gravity drainage processes, the key mechanism is not that of steam displacement. Rather, first, the bitumen is mobilized and drains under gravity. Second, the steam then fills in the now depleted zone which was previously filled with bitumen. Thus, the concept of displacement is not entirely fitting for thermal gravity drainage processes. This is especially the case where the flows are counter-current-this is the case when bitumen is mobilized above a steam zone and then drains downwards towards the base of the chamber. In this case, first, the bitumen is mobilized (heated), it then drains due to the density difference between the steam chamber below and the mobilized bitumen. Finally, the steam rises into the space that was once occupied by the bitumen and consequently heats more material above the steam. This propagation of mobilization, drainage, and then filling of the space is the basis for steam chamber rise and it is 
a counter-current flow process - the bitumen drains downwards whereas the steam rises upwards. Thus, from a heat transfer point of view, the steam movement into the depleted bitumen space is by convection, although prior to bitumen drainage, conduction of heat occurs warming the bitumen above the steam chamber. At the edge of the steam chamber, heat conduction occurs from the steam chamber outwards into the bitumen reservoir. In a similar manner to that at the top of the steam chamber, the bitumen is first heated and mobilized; second, due to the density difference between the steam chamber and mobilized bitumen, it drains under gravity down the chamber slope, and third, steam fills the now depleted zone. Thus, steam convection occurs with conduction beyond the chamber edge.

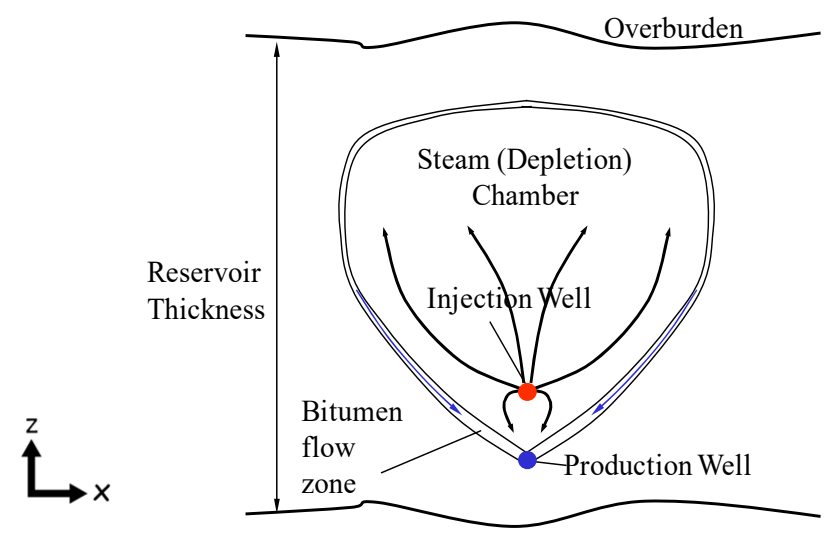

Figure 1. Cross-sectional view of the steam-assisted gravity drainage (SAGD) process.

In the study of thermal recovery processes, emphasis has mostly been on the steam-oil interface since that is where the majority of heat and mass transfer interactions are taking place. Nasr et al. [2] used lab scale experiment and numerical simulation to examine the effect of varying reservoir conditions (i.e., gas saturation and permeability) on the flow mechanisms observed in a SAGD process. Among others some of their major findings showed that at the steam-oil interface, higher reservoir permeability enhances convective heat transfer. They further concluded that for the same reservoir permeability, co-current flow of steam and water has no adverse effect on the steam propagation front whereas the draining steam condensate impedes the steam propagation front in counter-current flow. Sharma and Gates [3] examined fluid flow at the edge of the steam chamber in a SAGD process. Recognising the impact of oil saturation and relative permeability on the mobility of the displaced oil as heat is transferred, they derived a new theory to predict the oil drainage rate at the steam-oil interface for SAGD. Sharma and Gates [4] also investigated the heat transfer at the edge of steam chamber in a SAGD process. They accounted for the onset of condensate flow which induces heat transfer by convection. A new analytical model for heat transfer was derived with an apparent thermal diffusivity term. The apparent thermal diffusivity term accounts for both conductive and convective heat transfer at the edge of the steam chamber. Irani and Gates [5] investigated the convective heat transfer mechanism at the edge of the steam chamber. Their results showed that the convective heat flux normal to the edge of the steam chamber is significantly higher than the flux in the direction parallel to fluid flow hence can be ignored. In an analytical study, Irani and Ghannadi [6] compared the relative roles of conductive and convective heat transfer processes at the steam-oil interface in a SAGD process. They concluded that heat is still predominantly transferred by conduction irrespective of the high convective heat released in the water-saturated zone at the steam-oil interface.

Previous studies have also shown that steam fingering can induce further heat transfer in thermal recovery systems [7]. Fingering occurs and creates instability in the steam-oil interface since lower viscosity steam channels through $\mathrm{HO} / \mathrm{B}$ due to unfavorable mobility ratio. It is believed that this enhances the heat transfer area resulting to additional heat transferred to the bitumen reservoir [8]. The thrust of the research described here provides further insights on heat transfer and fluid flow dynamics beyond the steam-oil interface. 


\section{Reservoir Simulation Model}

The governing equation for multiphase flow in porous media is Darcy's law, given by:

$$
\boldsymbol{u}_{*}=-\frac{\boldsymbol{k}_{*}}{\mu_{*}} \nabla \Phi_{*}
$$

where $u$ is fluid velocity of phase ${ }^{*}, k$ is the effective permeability tensor of phase ${ }^{*}$ in the rock, $\mu$ is the viscosity of the phase, and $\nabla \Phi_{*}$ is the potential gradient of phase * (including both pressure and gravity terms), given by:

$$
\Phi=g\left(z-z_{\text {datum }}\right)+\int_{P_{\text {datum }}}^{P} \frac{d P}{\rho}
$$

where $g$ is acceleration due to gravity, $\rho$ is the density of the fluid, and $z$ is the elevation above the datum location [1]. Together with the material balance, this gives [1,9]:

$$
\begin{gathered}
\nabla \cdot\left[\frac{R_{\mathrm{sw}} k_{\mathrm{w}}}{\mu_{\mathrm{w}} \mathrm{B}_{\mathrm{w}}}\left(\nabla \mathrm{P}_{\mathrm{w}}-\rho_{\mathrm{w}} \mathrm{g} \nabla \mathrm{z}\right)+\frac{\mathrm{R}_{\mathrm{s}} \mathrm{k}_{\mathrm{o}}}{\mu_{\mathrm{o}} \mathrm{B}_{\mathrm{o}}}\left(\nabla \mathrm{P}_{\mathrm{o}}-\rho_{\mathrm{o}} \mathrm{g} \nabla \mathrm{z}\right)+\frac{\mathrm{k}_{\mathrm{g}}}{\mu_{\mathrm{g}} \mathrm{B}_{\mathrm{g}}} \nabla \mathrm{P}_{\mathrm{g}}-\rho_{\mathrm{g}} \mathrm{g} \nabla \mathrm{z}\right) \\
=\frac{\partial}{\partial \mathrm{t}}\left[\varphi\left(\frac{\mathrm{R}_{\mathrm{so}} \mathrm{S}_{\mathrm{o}}}{\mathrm{B}_{\mathrm{o}}}+\frac{\mathrm{R}_{\mathrm{sw}} \mathrm{S}_{\mathrm{w}}}{\mathrm{B}_{\mathrm{w}}}+\frac{\mathrm{S}_{\mathrm{g}}}{\mathrm{B}_{\mathrm{g}}}\right)\right]+\frac{\mathrm{R}_{\mathrm{so}} \mathrm{q}_{\mathrm{o}}}{\mathrm{B}_{\mathrm{o}}}+\frac{\mathrm{q}_{\mathrm{fg}}}{\mathrm{B}_{\mathrm{g}}}
\end{gathered}
$$

where subscripts $\mathrm{w}, \mathrm{o}$, and g refer to water, oil, and gas phases, respectively. $R_{s w}$ and $R_{s o}$ are the solution gas ratios in the oil or water phases, respectively, $k_{0}, k_{w}$, and $k_{g}$ are the effective permeabilities of oil, water and gas, respectively, and $B_{0}, B_{w}$, and $B_{g}$ are the formation volume factors for oil, water, and gas, respectively. For conductive heat transfer, according to Fourier's law, the rate of heat transfer is expressed by:

$$
\boldsymbol{q}=-k_{t h} \nabla T
$$

where $\boldsymbol{q}$ is the heat transfer flux, $\boldsymbol{k}_{\boldsymbol{t} \boldsymbol{h}}$ is the thermal conductivity tensor, and $T$ is temperature. For thermal systems where phase change can occur and accounting enthalpy changes, the total energy flux heat in $\mathrm{x}, \mathrm{y}, \mathrm{z}$ directions for isotropic formation thermal conductivity becomes [10]:

$$
\begin{gathered}
\frac{\partial}{\partial x}\left(-k_{t h} \frac{\partial T}{\partial x}+\sum_{i=1}^{n_{p}} u_{i, x} \rho_{i} h_{i}\right)+\frac{\partial}{\partial y}\left(-k_{t h} \frac{\partial T}{\partial y}+\sum_{i=1}^{n_{p}} u_{i, y} \rho_{i} h_{i}\right)+\frac{\partial}{\partial z}\left(-k_{t h} \frac{\partial T}{\partial x}\right. \\
\left.+\sum_{i=1}^{n_{p}} u_{i, z} \rho_{i}\left[h_{i}+g z /\left(J g_{c}\right)\right]\right)=\frac{\partial}{\partial t}\left[(1-\varnothing) M_{r}\left(T-T_{r e f}\right)+\varnothing\left(S_{w} \rho_{w} U_{w}+S_{o} \rho_{o} U_{o}+\right.\right. \\
\left.\left.S_{g} \rho_{g} U_{g}\right)\right]+Q
\end{gathered}
$$

where $h_{i}$ is the enthalpy of each phase, $M_{r}$ is volumetric heat capacity of the reservoir solids, $U_{*}$ is the internal energy of the different phases per unit mass, and $Q$, is the energy input from a source per unit volume.

The complexities that occur for thermal recovery processes is that many of the physical properties of the bitumen, rock, and water (steam) depend on pressure and temperature. This is especially the case for the viscosity of the bitumen; an example of the dependence of bitumen viscosity on temperature is displayed in Figure 2. Other complications that arise include the effect of multiphase flow, represented by relative permeability curves, and phase behavior. The amount of solution gas dissolved in the oil depends on temperature and pressure and amount of solution gas in the gas phase (the gas phase contains both the solution gas and steam vapor).

To solve the governing equations taking into account multiphase flow and heat transport, we use the STARS ${ }^{\mathrm{TM}}$ thermal reservoir simulator [12]. This simulator is based on the finite volume method and discretizes the reservoir domain into grid blocks. In STARS ${ }^{\mathrm{TM}}$, phase equilibrium is maintained at every time step in each grid block, as the mass and momentum balance defined by multiphase Darcy's law is solved simultaneously with the energy balance equation. Also, a K-value based compositional model is used to determine the PVT behavior of the phases, i.e., the solution gas solubility in bitumen (see [12] for more details). The nonlinear set of equations are solved by the Newton's method and integrated through time by using the Euler's method. 


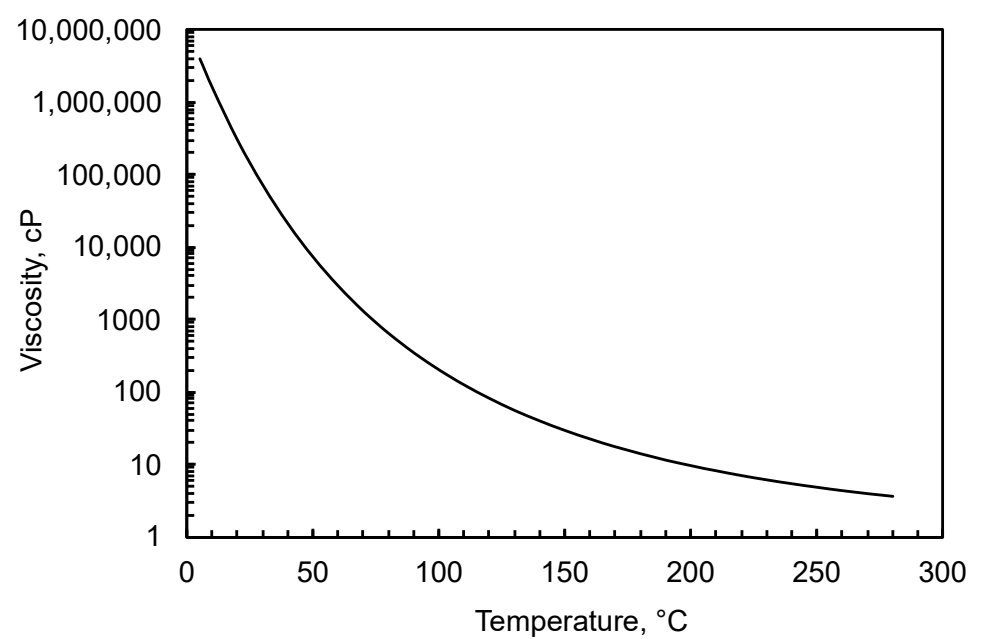

Figure 2. Oil sands viscosity versus temperature profile in Athabasca [11].

\section{Reservoir Model}

The domain used for the study are two 3D fine grid block models-one arranged in a horizontal direction, referred to as the Horizontal Elemental (HE) model, and the other in the vertical direction, referred to as the Vertical Elemental (VE) model, both displayed in Figure 3. The dimensions of the models are $1 \mathrm{~m}$ (wide) $\times 1 \mathrm{~m}$ (high) $\times 5 \mathrm{~m}$ (long) and $1 \mathrm{~m}$ (wide) $\times 5 \mathrm{~m}$ (high) $\times 1 \mathrm{~m}$ (long) for the HE and VE models, respectively. In both models, each of the grid blocks have dimensions of $1 \mathrm{~cm}$ in all directions leading to a total of five million grid blocks for each model. Refinement of the grid (to half the size) in length direction altered the pressure, temperature, and phase saturations by less than $0.1 \%$ and therefore the grid was considered as sufficiently refined. The properties of the models (both are homogeneous) are typical of that of an Athabasca oil sands reservoir, listed in Table 1. The initial oil saturation, porosity and permeability are $0.8,0.3$, and $6.5 \mathrm{D}$, respectively. The relative permeability curves were obtained from a history-matched SAGD model [13]. For viewing of results, the phase saturations are known in each grid block and thus, from the relative permeability curves, the relative permeability for each phase can be determined and plotted. For three-phase relative permeability, the oil relative permeability is determined from the Stone II Model.

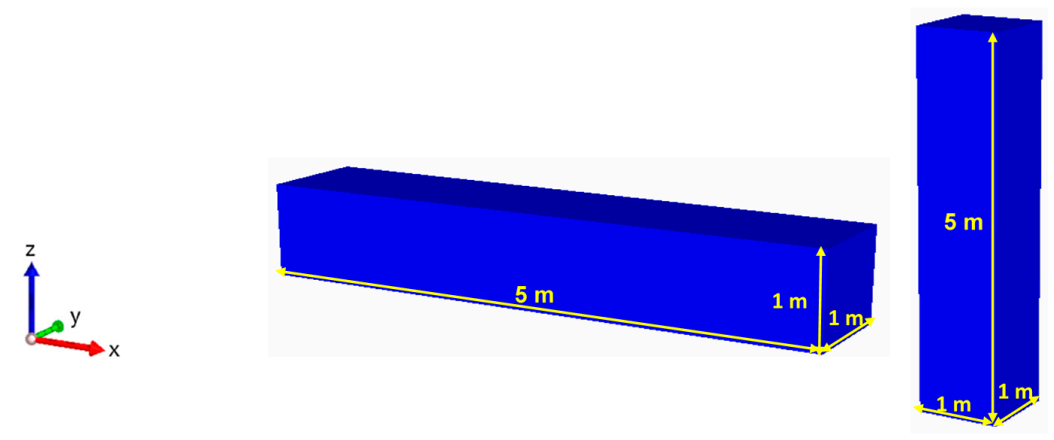

Figure 3. Three-dimensional views of the horizontal (left) and vertical (right) elemental reservoir simulation models. In both models, each grid block has dimensions of $1 \mathrm{~cm}$ in all directions leading to a total of five million grid blocks for each model. The boundary conditions are described in the text.

In the VE model, steam is injected into and fluids are removed from the bottom of the model. This mimic the top of a steam chamber with the intact oil sands above. In the HE model, steam is injected into and fluids are produced from the left end of the model. In both cases, steam is injected continuously at $4000 \mathrm{kPa}$ with steam quality 0.9 ; at this injection pressure, the volumetric flow rate 
is equal to about $1.21 \mathrm{~m}^{3} \mathrm{CWE} /$ day $(\mathrm{CWE}=$ cold water equivalent). The corresponding saturation temperature of the steam is $250{ }^{\circ} \mathrm{C}$.

Table 1. Reservoir properties used in thermal reservoir simulation model.

\begin{tabular}{|c|c|}
\hline Parameter & Value \\
\hline Initial temperature, ${ }^{\circ} \mathrm{C}$ & 10 \\
\hline Initial pressure, $\mathrm{kPa}$ & 2.670 \\
\hline$S_{\text {orw }}$ & 0.2237 \\
\hline $\mathrm{S}_{\mathrm{Wc}}$ & 0.15 \\
\hline$S_{\text {org }}$ & 0.005 \\
\hline $\mathrm{S}_{\mathrm{gc}}$ & 0.005 \\
\hline $\mathrm{k}_{\text {rwro }}$ & 0.5 \\
\hline $\mathrm{k}_{\text {rocw }}$ & 0.998 \\
\hline $\mathrm{k}_{\text {rogc }}$ & 0.824 \\
\hline $\mathrm{k}_{\mathrm{rg}(\text { Sorg })}$ & 1 \\
\hline Three phase relative permeability model (CMG, 2015) & Stone Model 2 \\
\hline Rock, overburden/understrata heat capacity, $\mathrm{kJ} / \mathrm{m}^{3}{ }^{\circ} \mathrm{C}$ (Butler, 1997) & 2.350 \\
\hline Rock thermal conductivity, kJ/m day ${ }^{\circ} \mathrm{C}$ (Butler, 1997) & 660 \\
\hline Bitumen thermal conductivity, $\mathrm{kJ} / \mathrm{m}$ day ${ }^{\circ} \mathrm{C}$ (Butler, 1997) & 12.5 \\
\hline Water phase thermal conductivity $\mathrm{kJ} / \mathrm{m}$ day ${ }^{\circ} \mathrm{C}$ (Butler, 1997) & 53.5 \\
\hline Solution gas to oil ratio, $\mathrm{m}^{3} / \mathrm{m}^{3}$ & 3 \\
\hline Methane K-value correlation, $K-$ value $=\frac{k_{v 1}}{P} e^{\frac{k_{v 4}}{T+k_{v 5}}}(\mathrm{CMG}, 2015)$ & $\begin{array}{l}\mathrm{k}_{\mathrm{v} 1}=1.368 \times 10^{5} \mathrm{kPa} \\
\mathrm{k}_{\mathrm{v} 4}=-7.5446 \times 10^{2}{ }^{\circ} \mathrm{C} \\
\mathrm{k}_{\mathrm{v} 5}=-4.8484 \times 10^{2}{ }^{\circ} \mathrm{C}\end{array}$ \\
\hline $\begin{array}{l}\text { Bitumen viscosity correlation (Mehrotra and Syrcek 1986) } \\
\qquad \ln \mu(\mathrm{cP})=\mathrm{A}+\mathrm{B} \ln \mathrm{T}(\mathrm{K})\end{array}$ & $\begin{array}{c}\mathrm{A}=5.45 \times 10^{5} \mathrm{kPa} \\
\mathrm{B}=-879.84^{\circ} \mathrm{C} \\
\mathrm{C}=-265.99^{\circ} \mathrm{C}\end{array}$ \\
\hline Bitumen density correlation (Gates, 2013) & $\mathrm{E}=1024$ \\
\hline$\rho\left(\mathrm{kg} / \mathrm{m}^{3}\right)=E+F T\left({ }^{\circ} \mathrm{C}\right)$ & $\mathrm{F}=-0.645$ \\
\hline Porosity & 0.30 \\
\hline Oil viscosity at initial temperature, $\mathrm{cP}$ & 1.3 million \\
\hline Oil saturation & 0.8 \\
\hline Water saturation & 0.2 \\
\hline Steam quality & 0.9 \\
\hline Permeability, mD & 6.5 \\
\hline
\end{tabular}

The boundary conditions on the models are as follows. At the side walls of the models, symmetry conditions are applied. For the VE model, at the top boundary of the model, no flow is permitted but heat losses are allowed according to Vinsome and Westerveld's [14] heat loss model. This model is an approximation for one-dimensional heat losses into an infinite top rock above the model which is at the initial temperature of the model. For the HE model, at the right boundary of the model, the same conditions are applied as that at the top of the VE model.

The models were simulated until the steam chamber, both flow and heat transfer, and other phase properties (such as the phase saturations and properties) had achieved a pseudo-steady state (that is, the properties and values were not changing relative to the edge of the steam chamber. For the purpose of this study, this was achieved after the values were changing by less than $0.1 \%$ ). In the VE and $\mathrm{HE}$ models, this occurred after 12 and 16 days of simulated time, respectively. Note, in the HE model, the temperature profile at 20 days (indicated by yellow line) overlaps the profile at 16 days, indicative of pseudo steady state condition. For analysis of the results, profiles of properties, pressure, velocities, and temperature were taken along the central axis of the models. Each simulation was solved on a $3.1 \mathrm{GHz}$ personal computer with 40 cores and took roughly 11 days to run. 


\section{Results and Discussion}

The profiles and visualizations of results for the VE model have been rotated 90 degrees to the right to provide an easier comparison with the results from the HE model. In both cases, the $x$-axis is the distance from the steam front and beyond into the intact oil sand. When profiles are compared, the solid and broken lines represent the VE and HE models, respectively.

Figure 4 shows the temperature profiles for the VE and HE models where the temperature versus distance beyond the steam-oil interface is displayed at different times. For the VE model, the profile is relatively steep, i.e., minimal temperature gradient beyond the steam-oil interface from early time (12 h) to 12 days. This suggests that heat transfer is by conduction and is uniformly transferred into the cold bitumen as described by the Fourier's law. It is also observed that after 12 days of steam injection $\sim 2.65 \mathrm{~m}$ of the reservoir is heated ahead of the steam front, i.e., showing a temperature rise rate of $\sim 20 \mathrm{~cm} /$ day. Notice that this is not the same as the steam rise rate. The HE model temperature profile is significantly different. Unlike the VE model, a greater temperature gradient is observed beyond the steam-oil interface. At early time (i.e., $\sim 12 \mathrm{~h}$ ) after steam injection, a relatively steep gradient is observed. This is when the steam front rises vertically (lateral growth of the interface is very slow at this time). The temperature profile at this time is similar to that of the VE model. As soon as the steam reaches the top of the model, the steam front begins to propagate laterally but non-uniformly as shown. Also displayed in Figure 4 are 2D images displaying the extent of the model that has been thermally altered.
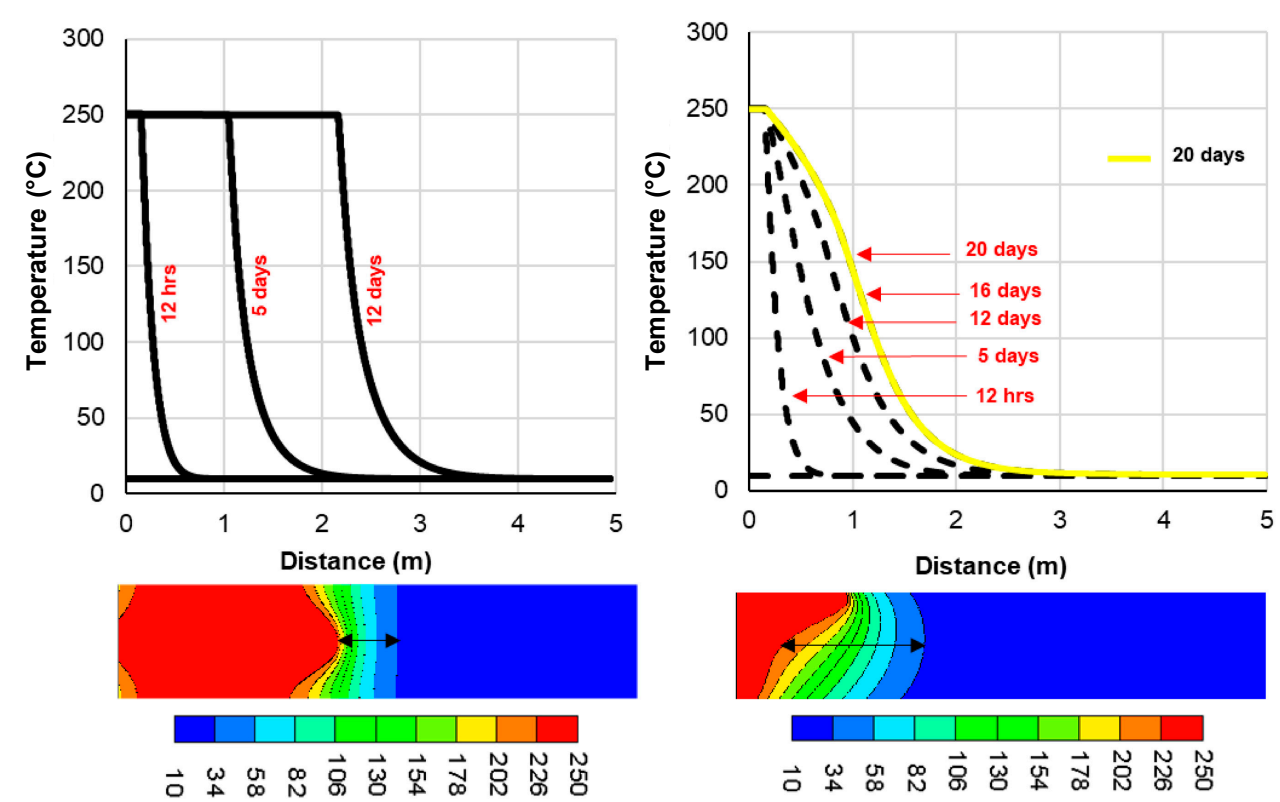

Figure 4. Temperature versus distance at different times for the Vertical Elemental (VE) (left) and the Horizontal Elemental (HE) (right) models. 2D images of the temperature profile at 12 and 16 days of steam injection are displayed underneath. Notice that for the HE model, at 20 days, temperature profile overlaps profile at 16 days. The VE model has been rotated by 90 degrees to the right.

The result shows that in the VE model, beyond the steam saturation interface, $\sim 20 \mathrm{~cm}$ of the model was thermally altered despite the high temperature rise rate. The HE model is significantly different in that, at the symmetry plane where the temperature profile is displayed, the steam interface is at a distance of $\sim 0.15 \mathrm{~m}$ but the thermally altered zone extends further up to additional $105 \mathrm{~cm}$ indicating that beyond the steam front, the depth of heat penetration is about 5 times higher (black arrows are used to show the extent of heat penetration). The enhancement in temperature observed in the HE model suggests additional heat transfer by means of heat convection. The result supports claims by previous studies $[4,5,15]$ which all show that there is a significant contribution of heat transfer by 
convective flow with the onset of hot condensate flow at the edge of the steam chamber. It also agrees with the analytical solution of Sharma and Gates [3] in which the apparent thermal diffusivity term accounts for both conductive and convective heat transfer at the edge of the steam chamber. This heat transfer thermally alters the temperature in the lateral direction as shown in the temperature profile but does not necessarily lead to mobilization of the oil. This is discussed in later sections.

Figures 5-7 show fluid saturation profiles ahead of the steam-oil interface for both models. The red, blue, and green curves represent the gas, water and oil saturation profiles, respectively. The brown lines in Figure 5 show the fraction of solution gas that is released at high temperature. At the steam interface, the brown lines show the amount of solution gas ex-solved from oil at high temperature. It is observed that at the steam front, up to about $40 \%$ more of the solution gas is ex-solved in the VE model compared to the HE model. This is because after exsolution, the gas rises upwards because of buoyancy forces. In both cases, the exsolved gas is ahead of the steam front which could act as insulation to the heat transfer to cold bitumen. The water saturation, displayed in Figure 6, rises sharply at the steam-oil interface as soon as the steam (gas) saturation drops to zero. Higher water saturation is observed ahead of the steam front for the HE model compared to that of the VE model. The increased water saturation is a result of hot condensate pooling ahead of the steam front. This condensate pool extends up to additional $60 \mathrm{~cm}$ in the HE model compared to that of the VE model where it is only $\sim 4 \mathrm{~cm}$ beyond the steam front. From the oil saturation profiles displayed in Figure 7 , the results reveal greater oil depletion as the steam is propagating vertically compared to the lateral direction. The oil saturation profile is also compared against the temperature profiles for both models. The VE model result shows that the oil saturation profile compares well with the temperature profile gradients (solid green and black lines). It reveals that at the oil saturation is a linear function of temperature consistent with results from previous studies $[4,16]$. The HE models display different results (broken green and black lines). Whereas the temperature profile shows that the reservoir has been thermally altered and bitumen mobilized up to a distance of $2 \mathrm{~m}$ beyond the steam-oil interface, the oil saturation profile indicates that most of the mobilized oil have not been drained because the maximum oil saturation is at $\sim 0.7 \mathrm{~m}$ (note the slight gradient in oil saturation). The VE model results have therefore shown that the effective displacement of bitumen from the pore space is a function of high temperature, i.e., heat transfer by conduction. However, Sharma and Gates [4] were able to show the contribution of the condensate velocity to the overall heat transferred to the cold bitumen when the steam injection pressure is higher than the initial reservoir pressure, and where there is increased condensate velocity. In a recent study, $\mathrm{Li}$ and Chen [17], modified the condensate velocity term in Sharma and Gates's [3] heat transfer model and proposed a modified heat transfer equation where they showed that convection provides a larger contribution to the heat transfer than convection at the steam-oil interface. What this study has further revealed is that as the steam is spreading in the reservoir, even though convective steam-based heat transfer is present and high and the reservoir temperature is altered, it does not translate to automatic/effective mobilization or drainage of the oil. It also shows the benefit of high temperature at the steam-oil interface.

The invasion of steam and condensate into the previously occupied pore space by bitumen, leads to changes in the saturation profiles of the fluid phases in the reservoir as shown above. As a result, distinct fluid regions are observed ahead of the steam saturation zone. These regions were identified based on the phase saturation and temperature profiles seen in both models. Figures 8 and 9 display 2D images of the oil saturation profiles for the VE and HE models, respectively. Ahead of the steam front (i.e., at a temperature isosurface of $250^{\circ} \mathrm{C}$ ), three distinct fluid regions are identified: A-rich oil and hot water zone, B-mobilized oil zone, and C-native (original) bitumen zone. Each fluid region is compared for both models but displayed separately for clarity. Ahead of the steam saturated zone, there is a spike in gas and oil saturation. This is due to ex-solution of solution gas as the pressure declines at the edge of the chamber associated with the collapse of steam vapor to liquid. Zone B represents the region where bitumen has been mobilized in response to heat but it has not completely drained-it is richly oil saturated. The temperature and oil saturation profile gradually increases 
until they reach the native reservoir conditions (Zone C) where the oil is immobile. The mobilized oil, because it is warmer, fingers into the cold (native) bitumen due to its lower viscosity than that of the cool bitumen. This thermal fingering can result in instability creating an additional form of heat transfer to the cold bitumen. The thermal fingering is more dominant in the VE model compared to that in the HE model.

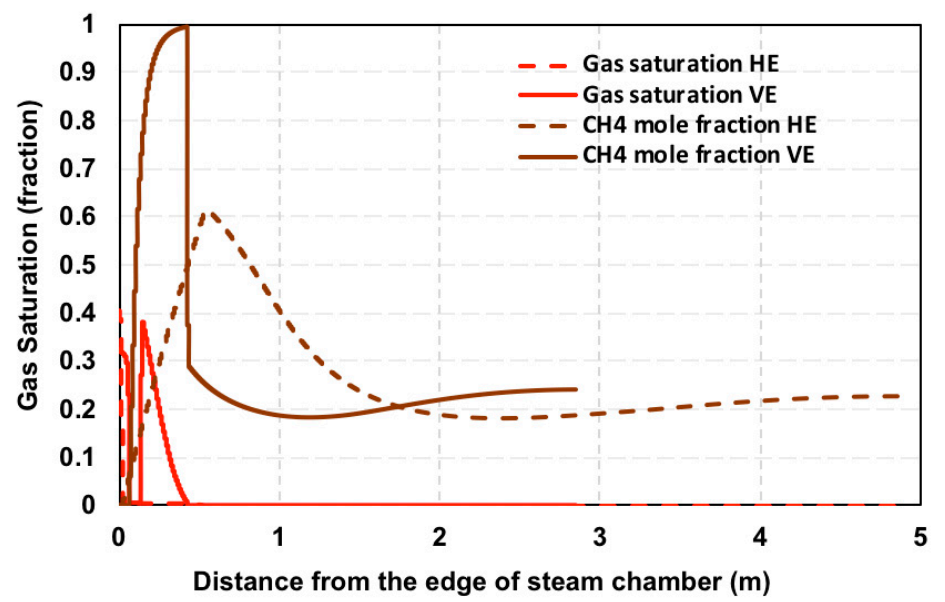

Figure 5. Gas saturation profile and gas mole fraction of methane, i.e., fraction of solution gas ex-solved into the gas phase versus distance for the VE and HE models.

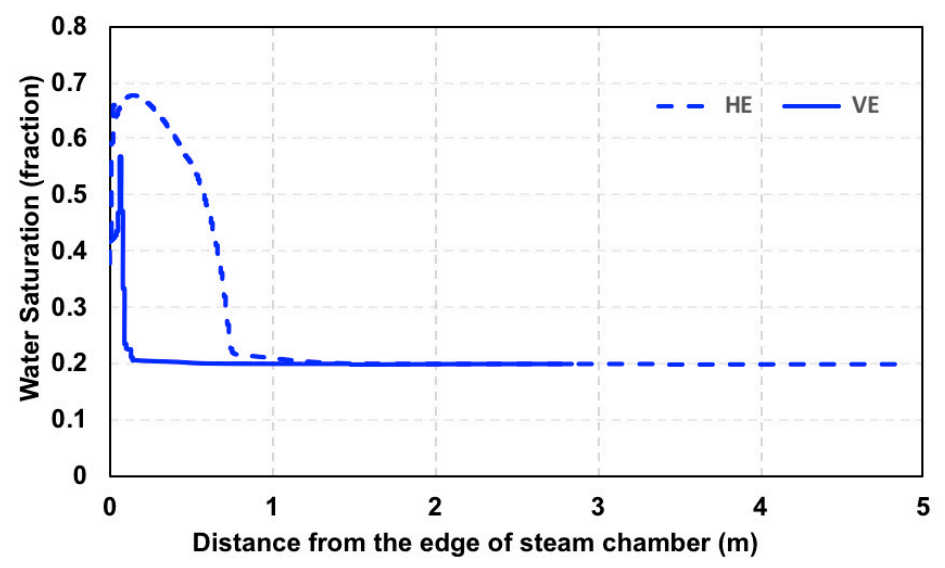

Figure 6. Water saturation profiles versus distance for the VE and HE models.

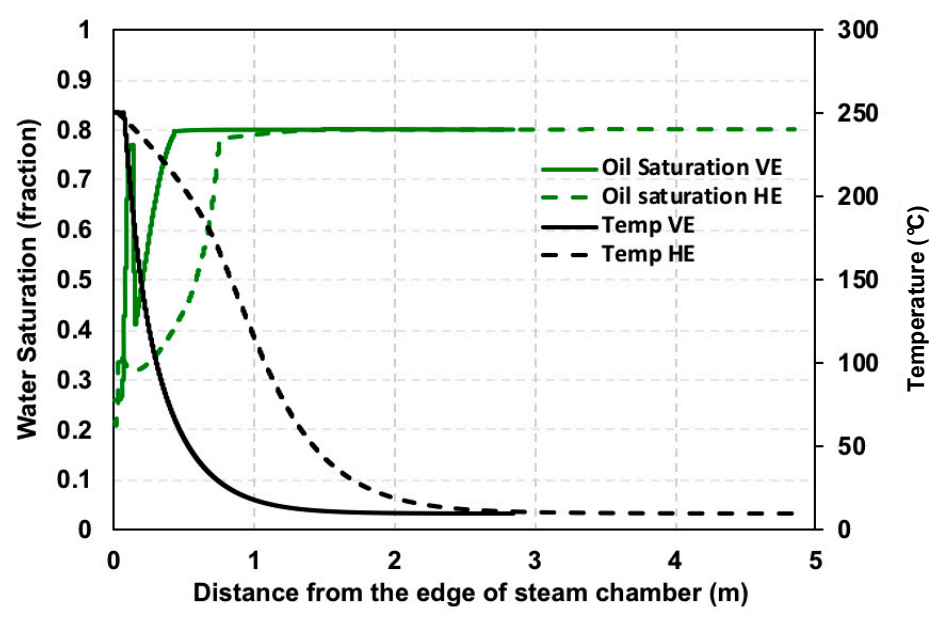

Figure 7. Oil saturation and temperature profiles versus distance for the VE and HE models. 


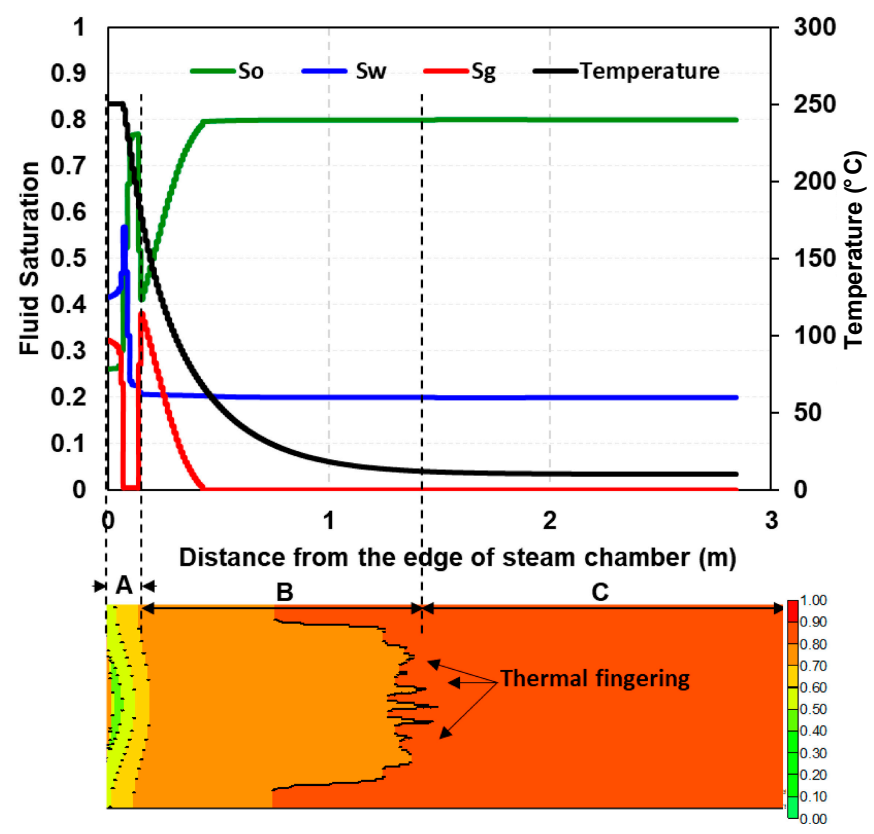

Figure 8. Phase saturations and temperature profiles versus distance together with 2D image of the oil saturation profile (below) indicating distinct fluid regions $(\mathbf{A}-\mathbf{C})$ observed in a cross section of the VE model. The VE model has been rotated by 90 degrees to the right and the width of the model has been exaggerated twice for clarity.

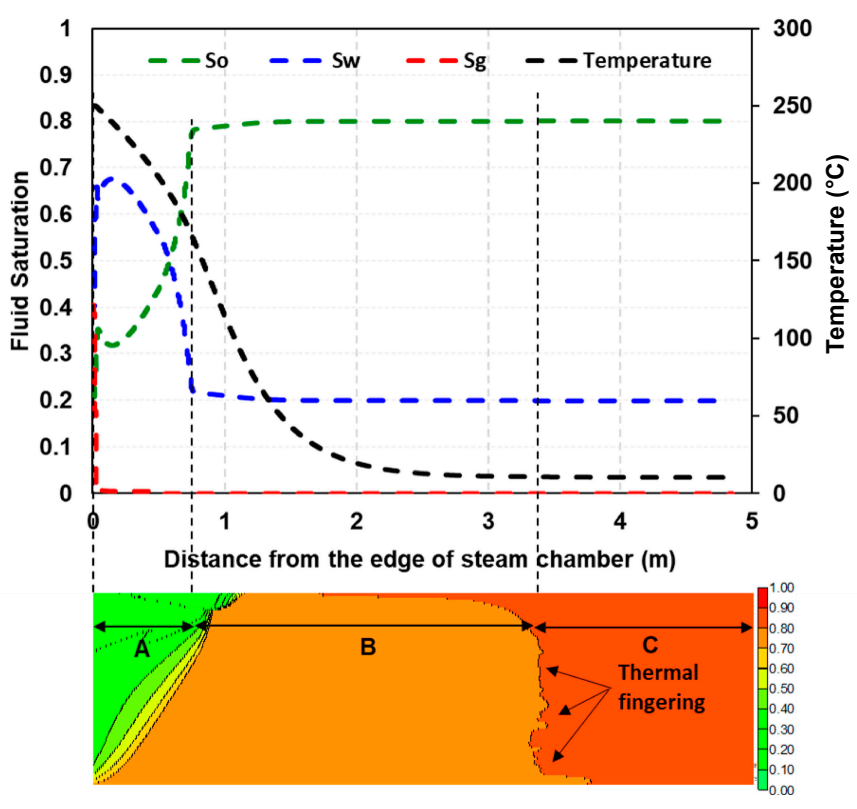

Figure 9. Phase saturations and temperature profiles together with $2 \mathrm{D}$ image of the oil saturation profile (below) indicating distinct fluid regions (A-C) and thermal fingering observed in a vertical cross section of the HE model. The width of the model has been exaggerated twice for clarity.

At the edge of the steam chamber is a pool of liquid (condensate and oil), i.e., Zone A observed in the HE model. As shown in Figure 9, this region is very thick compared to that in the VE model. In this region, the mobility of the oil is very low. The temperature declines as hot water transmits its sensible heat to the cold bitumen. The fluid saturation then transitions into a rich mobile oil zone, Zone B. This mobilized oil zone shows a steep gradient of the oil saturation compared to the temperature profile. This implies that the thermal alteration of the reservoir in that zone did not translate to displacement of mobilized oil. Another reason is that the relatively large pool of solution gas exsolved from the 
oil at that point could be acting as insulation to heat transfer. Zone $C$ is the native reservoir zone. Fingering of the mobile oil into the cold (native) bitumen is also present. However, this is smaller in extent compared to that of the VE model.

Figures 10 and 11 show how the distribution of heat is transferred by conduction and convection in the different fluid regions described above for the VE and HE models, respectively. The temperature profiles in Figure 4 indicate that heat transfer is dominantly by conduction in the VE model and by conduction and convection in the HE model. To illustrate this further, profiles of the heat conductive and convection energy transfer rate, i.e., the ratio of either conductive or convective energy to the gross rock volume, was examined for both models. The temperature and gas saturation profiles are also displayed. The turquoise blue and magenta color lines represents the conductive and convective heat transfer terms, respectively. For the VE model, Figure 10 shows that at peak water saturation (same as Zone A described above), there is a corresponding spike of the convective heat transfer term. This can be attributed to the high heat capacity of water and also high temperature at that point. Notice that the peak convective heat term is small. A similar magnitude of heat transfer but opposite in magnitude is transmitted by conduction. In the HE model, Figure 11 shows that the peak convective heat rate is observed at the steam-oil interface where there is a thin pool of steam condensate. The convective heat transfer is lower but extended in the high water saturated zone i.e., Zone A above, i.e., about $1 \mathrm{~m}$ away from the steam-oil interface specifically in the high oil saturated zone, i.e., Zone B. This implies that heat is transferred from the flowing hot oil into the cold bitumen. The heat conduction rate is observed to decline from the steam front in a similar trend as the temperature profile until it reaches its initial saturation condition. The results also reveal that the conductive heat transfer rate in the VE model is up to eight orders of magnitude higher than that of the HE model. A similar trend is observed for convective heat transfer. It also shows that more heat is transferred in the vertical translation of the steam chamber but the depth of penetration into the cold oil sands is limited.

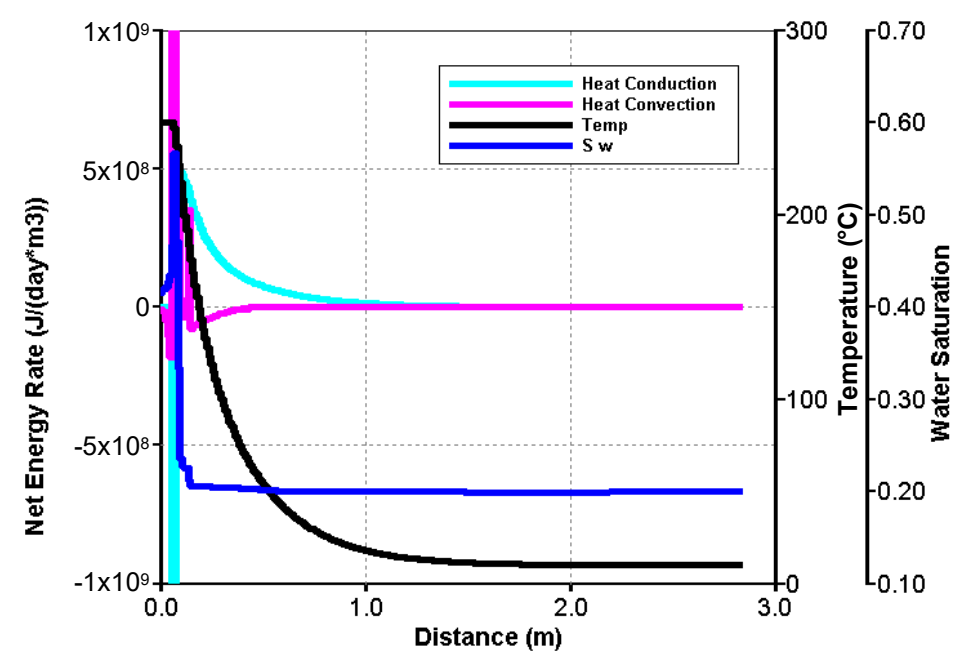

Figure 10. Conductive and convective heat transfer rates versus distance compared with temperature and water saturation profiles for the VE model.

Steam fingering is a common phenomenon that occurs due to unfavorable mobility ratios when less viscous fluid comes in contact with a more viscous fluid. Previous studies on thermal processes especially in SAGD show that steam fingers into the cold bitumen at the steam-oil interface. Steam fingers of centimeter length scales have been reported in experimental and numerical field simulations of SAGD processes [4,18]. Analytical studies by Gotawala and Gates [7] also estimated the height of steam fingers to be of order of millimeters to tens of centimeters. Whereas it was originally believed that the linear instability that arises at the steam interface will result in non-uniform heating of the bitumen leading to poor sweep efficiency, Zhu et al. [8] show that linear instability at the steam-oil 
interface is induced by ex-solution of solution gas from bitumen. They also show that fingers could be beneficial to the heat transfer process as it increases the contact area for heating.

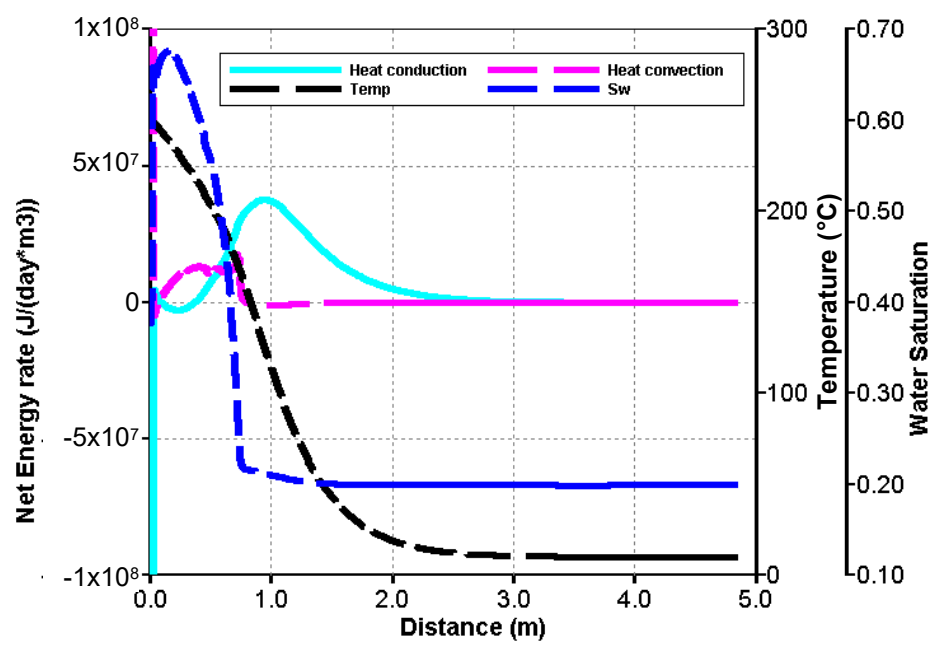

Figure 11. Conductive and convective heat transfer rates versus distance compared with temperature and water saturation profiles for the HE model.

To evaluate the occurrence of these fingers as the steam translates spatially in the reservoir, Figures 12 and 13 display exaggerated 2D images of ternary diagram at the steam front. These images are examined in vertical plane at days 12 and 16 of steam injection in the VE and HE models, respectively. The ternary diagram shows the distribution of water (blue), gas/steam (pink) and oil (green) in the reservoir. The result for the VE model (Figure 12) reveal that there are no steam fingers protruding directly into the oil phase. Instead, water percolates through the condensate zone and later transition into multiple layers with varying fluid saturations are observed ahead of the steam saturation zone. To further illustrate the absence of fingers at the steam front, Figure 13 shows 3D images of the VE and $\mathrm{HE}$ temperature distributions. It highlights a $250{ }^{\circ} \mathrm{C}$ temperature isosurface which identifies the steam-oil interface. A 3D image of the oil saturation is also displayed. A 0.8 oil saturation isosurface (orange surface) shows where the native bitumen is located. In between the steam temperature isosurface and the native bitumen is the transition from steam to condensate and mobile oil, i.e., Zones B and C described above. The shape of the temperature isosurface is like a finger but the protrusion is not directly at the oil interface. Instead, as described earlier, finger-like structures from the mobilized (warmer) oil zone are seen protruding into the cold bitumen. The scenario is different in the HE model. As shown in Figure 14, a stable steam interface is observed. The native bitumen zone is still ahead of the steam front. Viscous fingering of the warm mobilized oil into the cold bitumen is seen but is not as severe as is the case with the VE model. This result has therefore shown that contrary to results from previous studies, convective of warm oil fingers are the most evident form of fingering at the edge of the chamber.
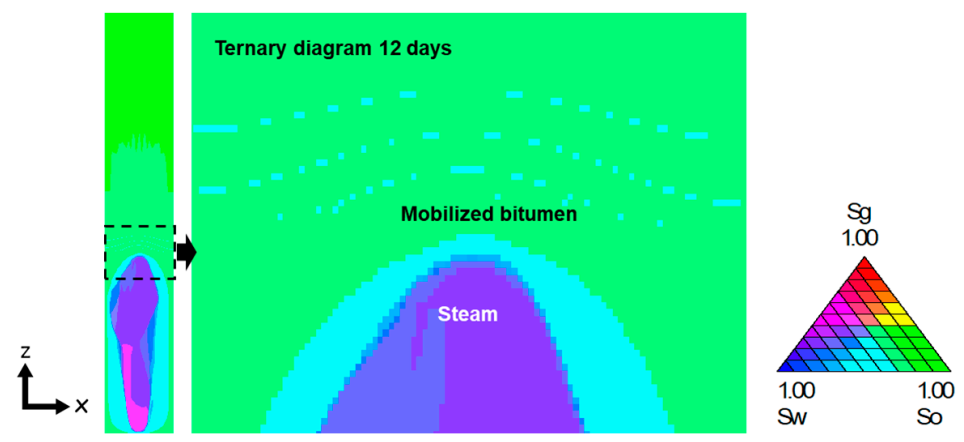

Figure 12. Cross section of the ternary diagram for the VE model. A section of the 2D image indicated by black dashed square has been zoomed in. 


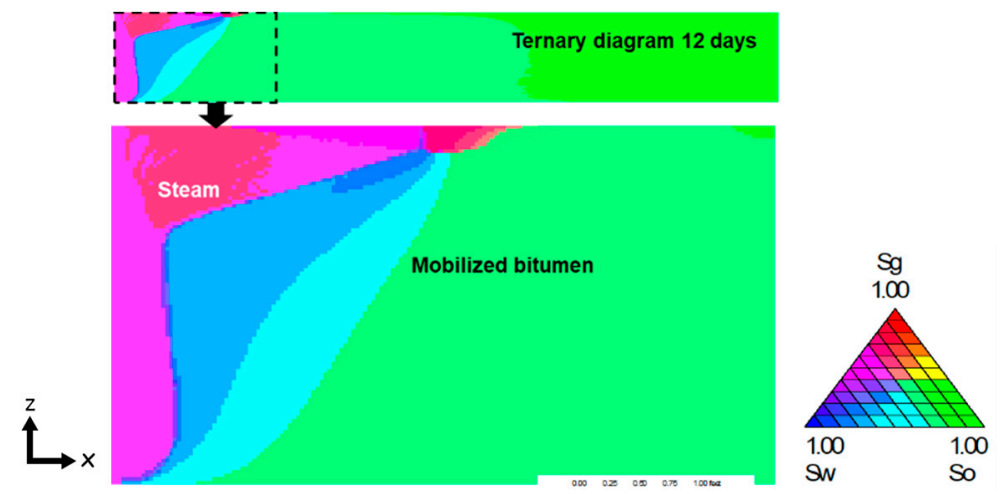

Figure 13. Cross section of the ternary diagram for the HE model. A section of the 2D image indicated by black dashed square has been zoomed in.
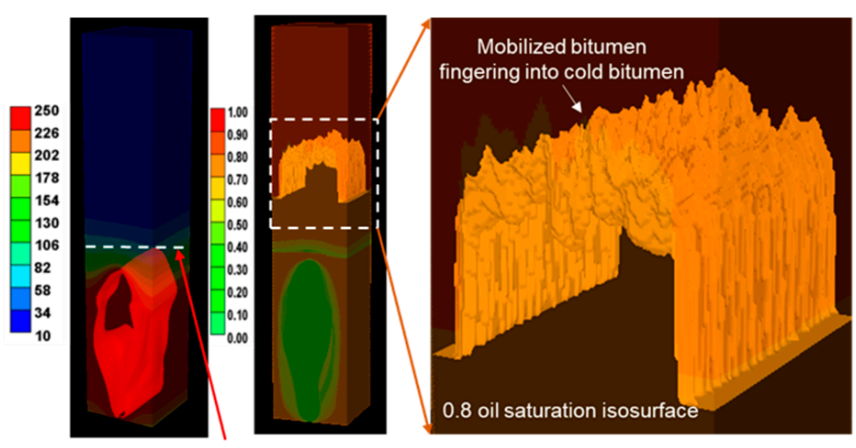

Position of steam interface $\left(250^{\circ} \mathrm{C}\right.$
relative to native (cold) bitumen
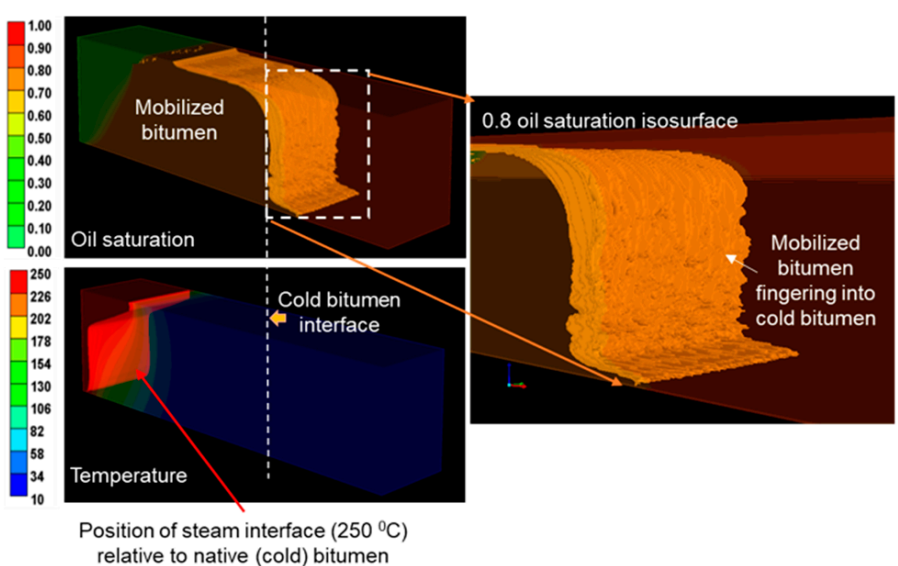

Figure 14. 3D images of the temperature and oil saturation isosurfaces of the VE (top) and HE (bottom) models respectively. The red isosurfaces are at $250{ }^{\circ} \mathrm{C}$ indicating the steam saturation boundary. The orange isosurfaces marks the 0.8 oil saturation indicating the mobile oil boundary. The enlarged images on the right show fingering of the mobilized (warm) bitumen into the cold (native) bitumen.

As heat is transferred into the reservoir, in the pore space, bitumen is mobilized and replaced by steam (gas) and hot condensate (water). This induces multiphase flow of fluids at the steam front. Figure 15 compares the profiles of the oil, water, and gas relative permeability, respectively, for the $\mathrm{HE}$ and VE models. The result shows that at the steam-oil interface, the relative permeability of the rock to oil is similar for both models. The values are initially very low, i.e., almost zero in the depleted zone but rises significantly beyond the steam interface as a result of increasing oil saturation. The case is different for the relative permeability to water for both models. In the HE model, a peak of 0.055 is observed at the steam-oil interface which decreases as it moves away from the edge of the steam front. Notice that the high relative permeability to water is extended up to about $50 \mathrm{~cm}$ away from the steam front. 
The peak relative permeability to water observed at the steam front for the VE model is suggestive of hot condensate pooling at the steam-oil interface. The very low relative permeability values suggest that the volume of condensate is very small but could potentially lead to a counter current flow with steam. Previous studies have however argued that this water will eventually drain due to the action of gravity and the steam will act as a blanket and prevents drainage into the steam-saturated zone. The gas relative permeability profiles displayed for both models (Figure 15) are similar. The increased gas relative permeability levels observed ahead of the steam front for the VE model are due to ex-solution of solution gas from the bitumen. The gas relative permeability seen in both models is similar to the steam chamber extent in both models because as observed beyond the steam front, gas mobility is zero.
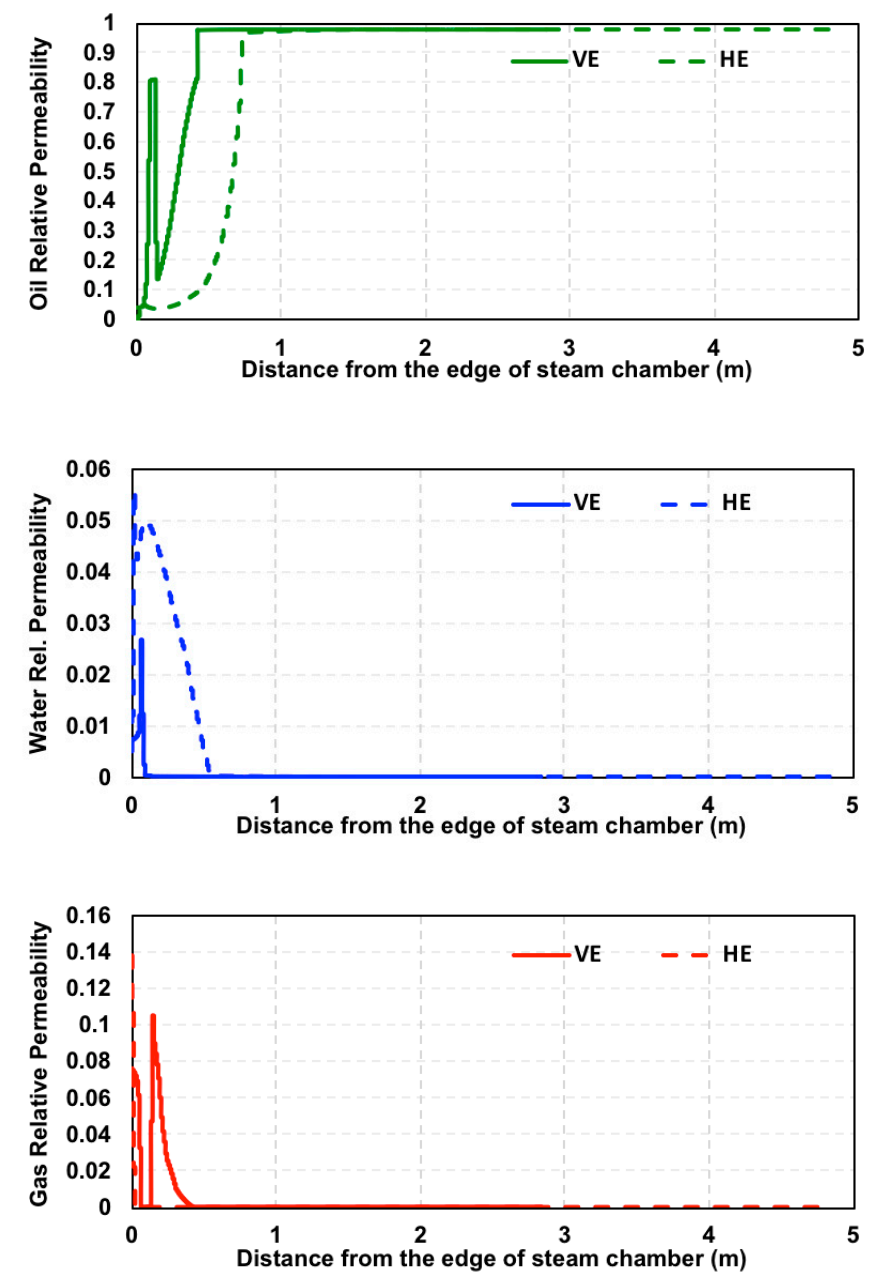

Figure 15. Oil relative permeability (top), water relative permeability (center) and gas relative permeability profiles (bottom) versus distance for the VE and HE models.

The oil viscosity profiles (purple lines) for the VE and HE models are presented in Figure 16. The HE model results indicate that the viscosity profile shows that the thermally altered zone extends to $\sim 2 \mathrm{~m}$ as shown in the Figure 16. It also shows the response of bitumen viscosity to increased temperature. The viscosity profile is also compared against the temperature profile for both models. The result reveals the extent of mobilized bitumen in response to increased temperature. For the HE model, the increased volume of mobile oil is attributed to additional heat transfer from convective flow of hot condensate accumulating ahead of the steam front. 


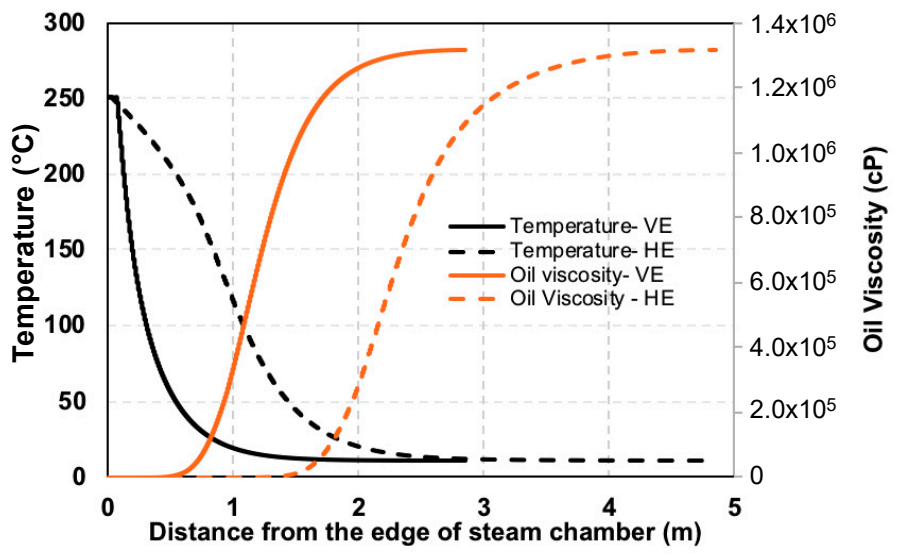

Figure 16. Oil viscosity and temperature profiles versus distance for VE and HE models.

Figure 17 compares the oil phase mobility profiles (i.e., the ratio of the effective permeability to the viscosity of the oil phase) for the VE and HE models beyond the edge of the steam-oil interface. The results reveal that for the HE model, the most mobile oil $(350 \mathrm{md} / \mathrm{cP}$ ) is at a distance of $\sim 70 \mathrm{~cm}$ ahead of the steam interface consistent with Sharma and Gates [3] observation that the most mobile oil was beyond the edge of the steam chamber (viewed in the direction perpendicular to the producer well) in a SAGD process. This increased oil mobility is sustained further into the reservoir $(\sim 1 \mathrm{~m})$ before it declines to zero. The profile for the VE model shows a relatively higher oil mobility but unlike the HE model it is only sustained for a short distance beyond the steam edge. The high oil mobility seen for both models can be attributed to the exponential reduction of the oil viscosity and high relative permeability. However, the volume of mobilized oil drained in the HE model is much lower than that of the VE model considering the extended area that was thermally altered. This is attributed to relative permeability effects. As the heat is transferred by the convective flow of hot condensate into the reservoir, the oil saturation decreases and so too does the oil relative permeability. The consequence is reduced effective permeability which leads to lower oil mobility. Another reason is the role of the gravity and viscous forces on the flow of the mobilized oil. In the VE model, due to the exponential reduction of the oil viscosity at the steam front, the viscous force is negligible and the oil is drained predominantly by gravity force. Whereas in the HE model, as the steam front propagates laterally, viscous drag effect sets in as the bitumen gets colder with horizontal distance. These counters the effect of the gravity force and pressure acting on the mobilized oil and as such the oil drainage declines.

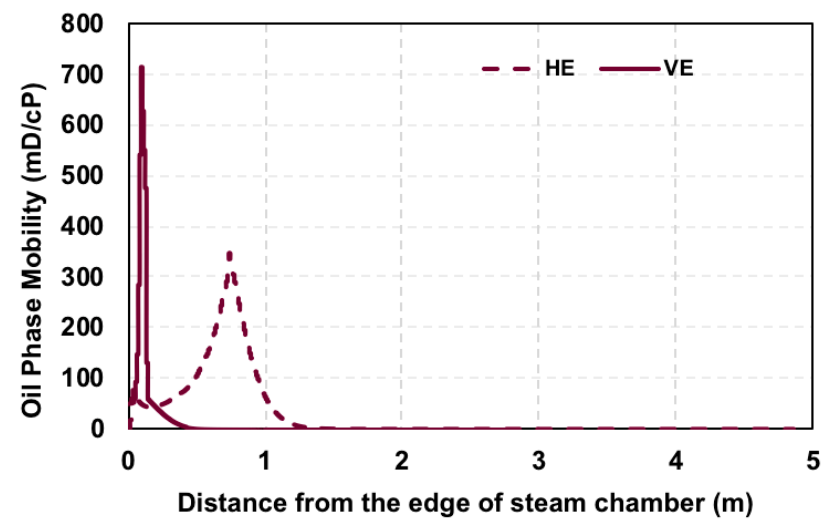

Figure 17. Oil phase mobility profile versus distance for VE and HE models.

Figures 18-20 are used to illustrate the transitions that occurs in the VE model as heat is transferred from steam to the cold bitumen. The section of the reservoir that is exaggerated for better visualization is highlighted by broken black lines on the image of the full length of the model. Figure 18 displays 2D images of the temperature, oil viscosity, saturation, and phase mobility profiles for the VE model 
in the vertical plane at early time i.e., 8 hours after steam is injected. The temperature distribution shows the boundary of the steam saturated zone (i.e., area where temperature is at $250{ }^{\circ} \mathrm{C}$ ). As heat is lost from the steam, a small temperature gradient is observed but the impact on the oil viscosity is very high. The extent of the model where the viscosity has been exponentially reduced is up to $300 \%$ compared to the temperature. As the oil viscosity drops, it mobilizes the oil creating a mobile oil zone as seen in the oil saturation profile. The oil saturation profile is similar to the oil viscosity profile. But in spite of the large area of mobilized oil, the oil phase mobility is relatively low. This is due to relative permeability effects described above. Although the most mobile oil region is at the top of the model, gravity is not sufficient to counter the viscous drag and pressure forces to drain the oil downward. After 5 days of steam injection, Figure 19 shows that a higher volume of steam is flowing upwards as it displaces the mobilized bitumen. Compared to early time, a relatively larger temperature gradient is observed as the steam front begins to deform the interface of the cooler bitumen areas ahead of it. The slightly dome shaped steam front at early time is now beginning to look like a big finger. Ahead of the steam front, the viscosity of over a meter length of the model has been drastically reduced which also increases the extent of the mobilized oil zone. At this time, the most mobile oil is no longer at the front of the steam front (see the oil phase mobility profile) but has drained counter-currently to the steam due to the action of the gravity force. Further ahead of the steam front, undulations are observed at the interface between the mobilized oil zone and cold bitumen (indicated by the black arrow in the oil saturation profile). This shows that the less viscous oil is trying to finger into the cold higher viscosity bitumen. The resolution of this model has made it possible to visualize this boundary condition. Figure 20 displays images of the profiles at quasi-steady state, i.e., 12 days after steam injection. The temperature gradient is the same as Day 5, the height of the protruding steam interface is also the same. However, the oil saturation shows a boundary condition just ahead of the steam interface where the oil saturation is slightly elevated. This is misleading as Figure 21 shows that at that point, solution gas ex-solved from the oil. At the mobile and native bitumen interface, the fingering of the less viscous oil into the cold more viscous bitumen is more severe and clearly seen in the oil saturation profile. The oil saturation profile displayed in Figure 20 shows exaggerated sections of the steam and mobile oil interface as well as the interface between mobilized oil and native bitumen. From the oil mobility profile displayed, the most mobile bitumen is draining downwards in response to gravity force. At this time, gravity is dominant because viscous drag is significantly reduced and the density difference between the oil and steam is greater.

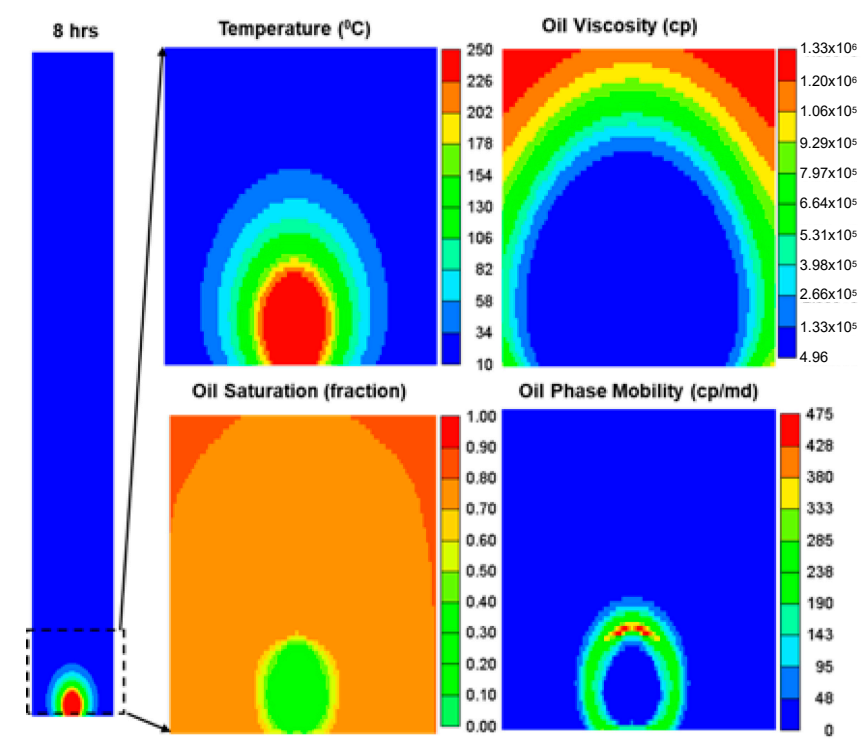

Figure 18. 2D images of the temperature, oil viscosity, oil saturation and oil phase mobility distributions in the VE model after 8 hours of steam injection. Zoomed in views are displayed of the region enclosed by the dashed black line square. 

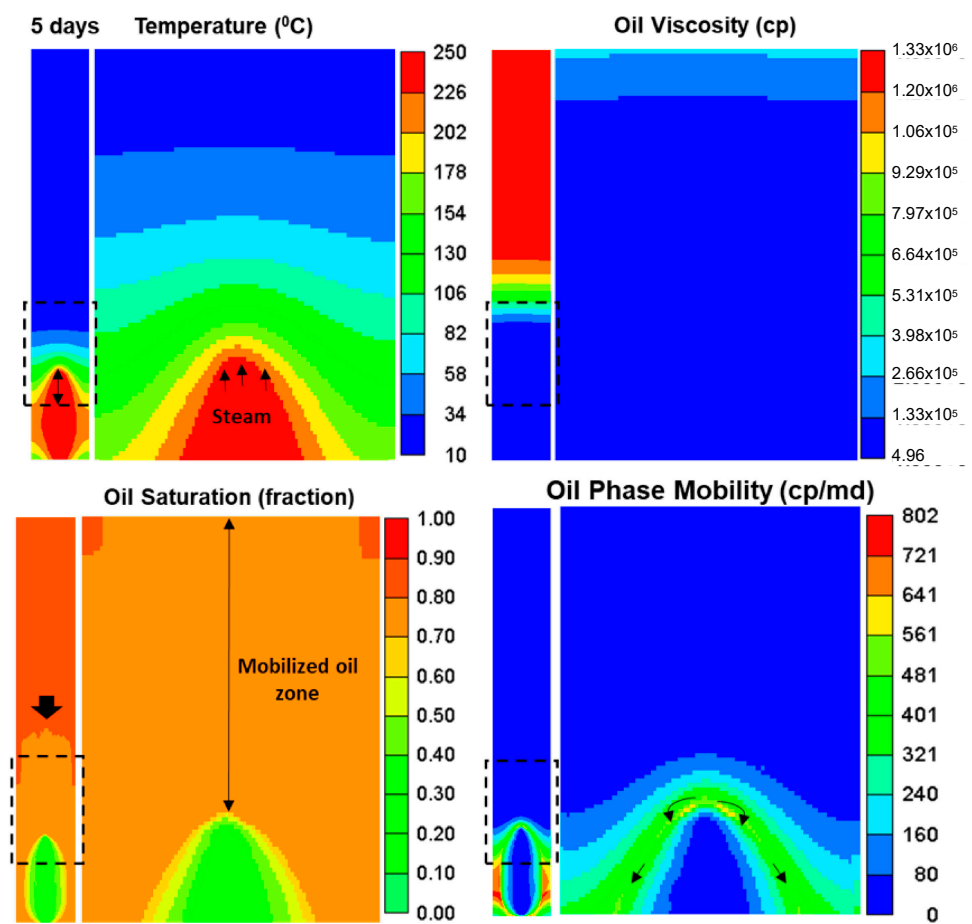

Oil Phase Mobility (cp/md)

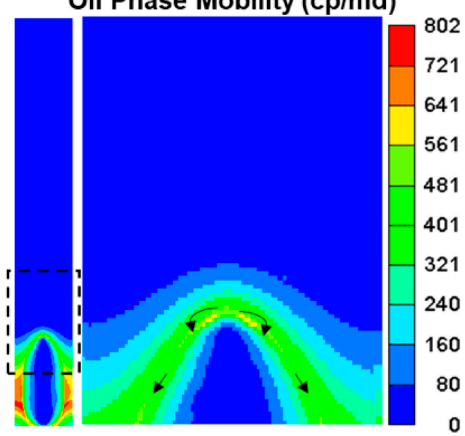

Figure 19. 2D images of the temperature, oil viscosity, oil saturation and oil phase mobility distributions in the VE model after 5 days of steam injection. Zoomed in views are displayed of the region enclosed by the dashed black line square.
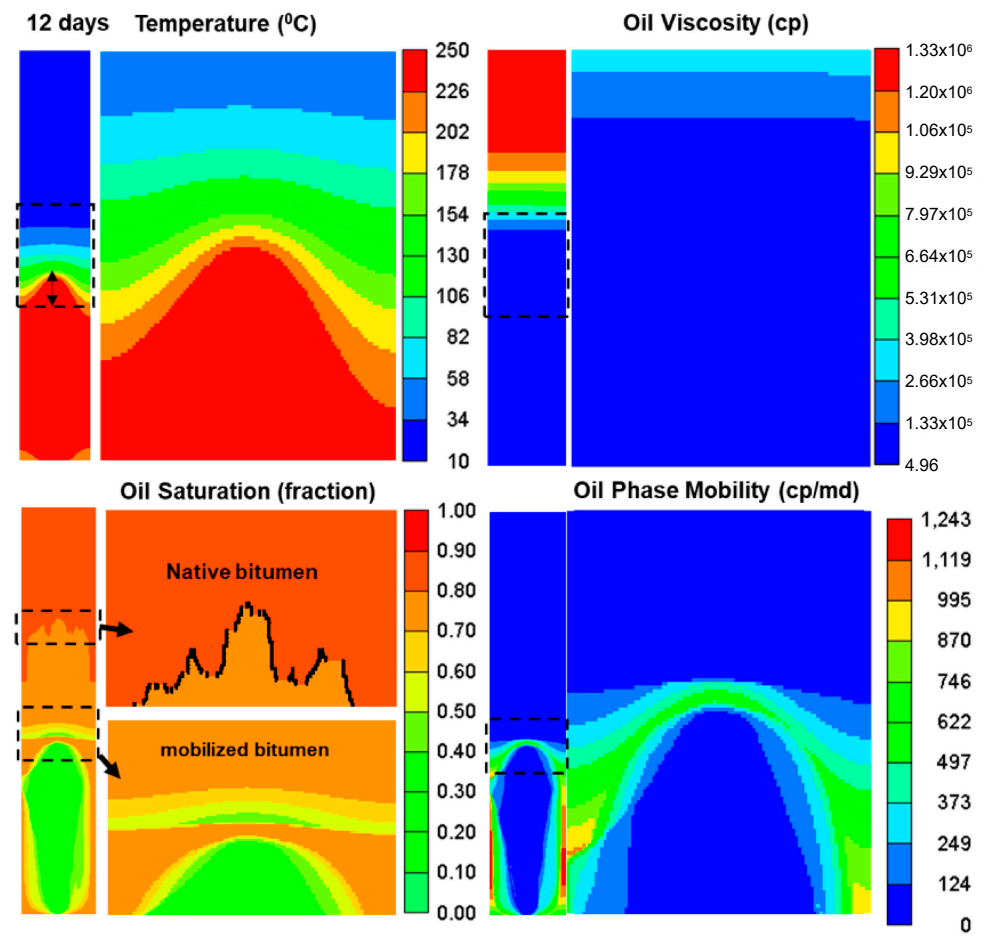

Figure 20. 2D images of the temperature, oil viscosity, oil saturation and oil phase mobility distributions of the VE model after 12 days of steam injection. Zoomed in views are displayed of the region enclosed by the dashed black line square. 


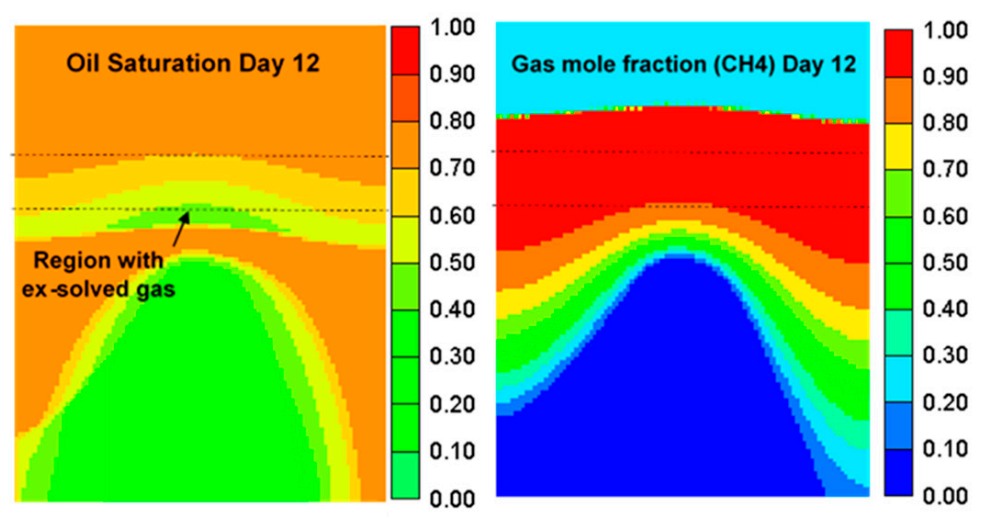

Figure 21. 2D images of oil saturation (left) and gas mole fraction (CH4) (right) distributions at the steam-oil interface for the VE model.

The transitions that occur in the HE model reservoir through different times are displayed in Figures 22-24. Similar to the VE model, 2D images of the temperature, viscosity, oil saturation and oil phase mobility profiles in the vertical plane are displayed. As soon as the steam starts spreading, not much changes are observed. The steam front is sharp and stable. The mobility of the oil phase ahead of the steam front mobility is relatively low, again confirming earlier assertions on the relative permeability effects on its mobility despite been reduced oil saturation.

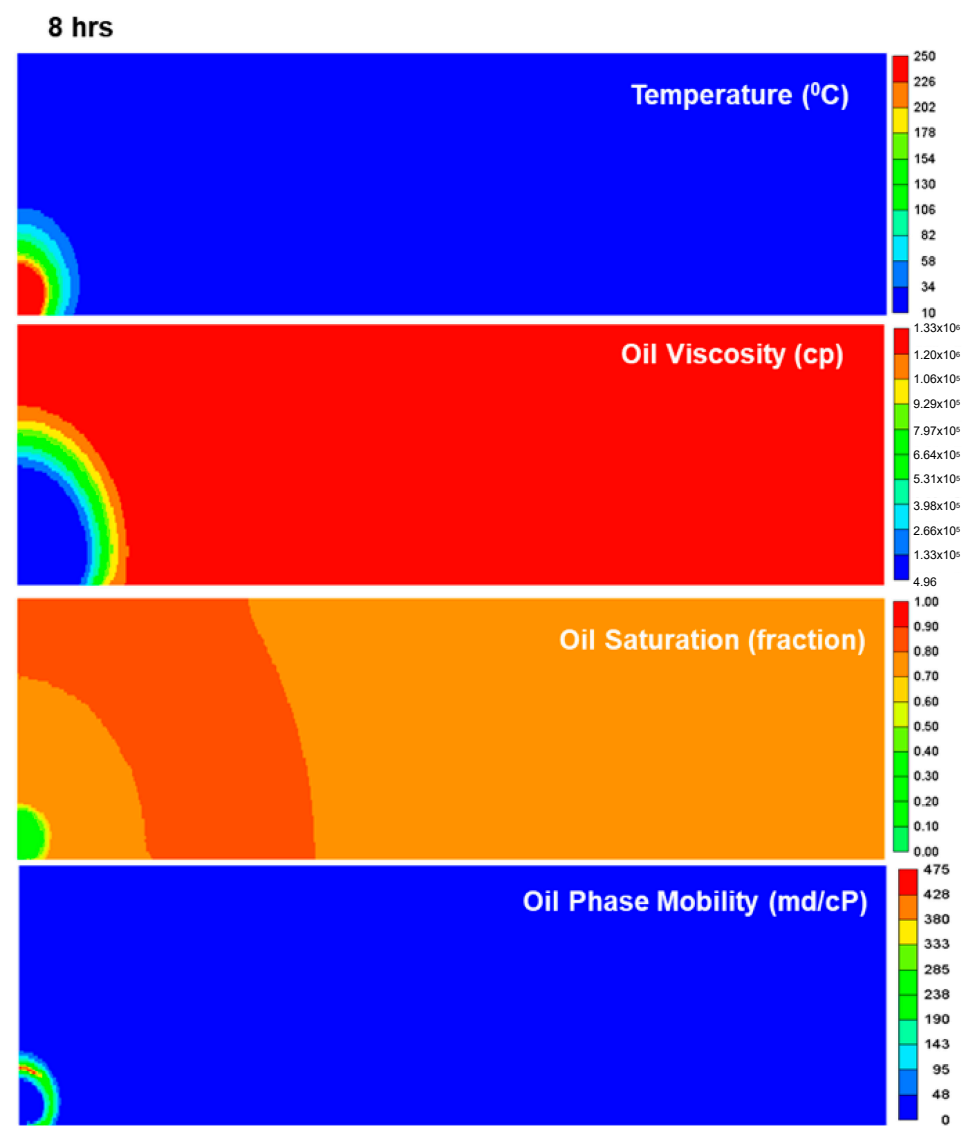

Figure 22. 2D images of the temperature, oil viscosity, oil saturation and oil phase mobility distributions of the HE model after 8 hours of steam injection. The height of the image has been exaggerated by two times. 


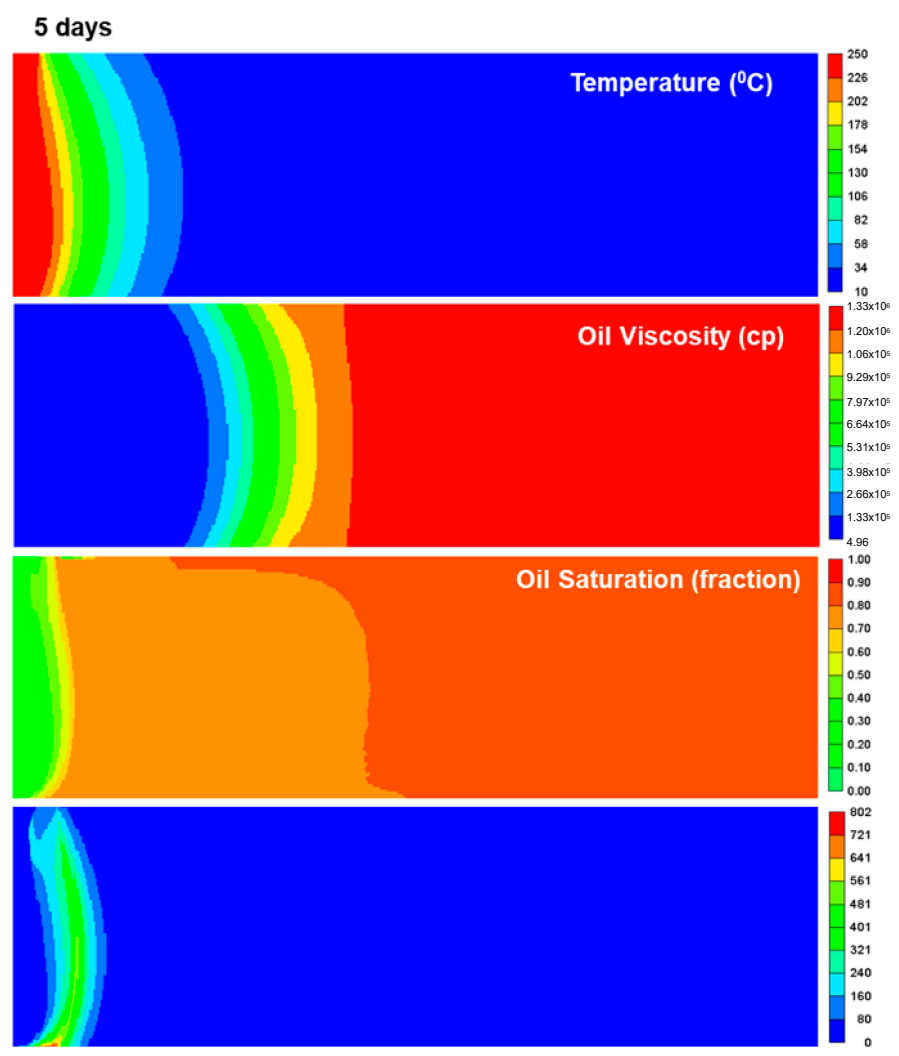

Figure 23. 2D images of the temperature, oil viscosity, oil saturation and oil phase mobility distributions of the HE model after 5 days of steam injection. The height of the image has been exaggerated by two times.

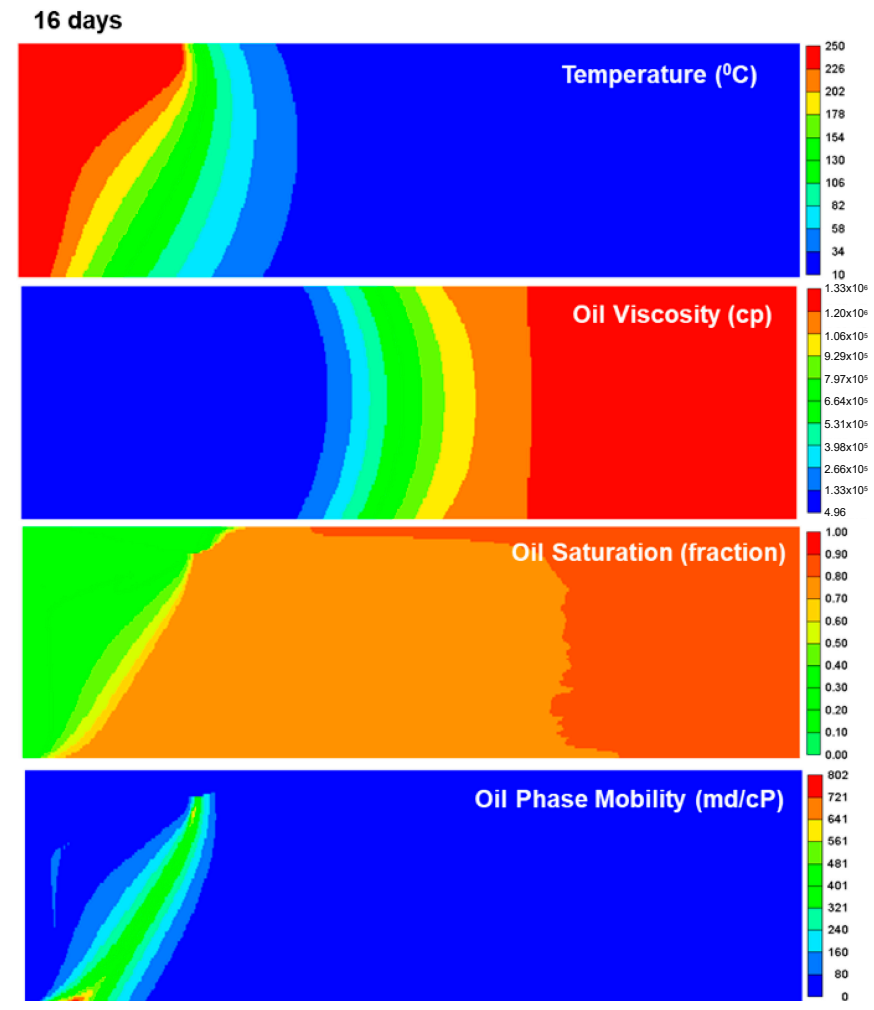

Figure 24. 2D images of the temperature, oil viscosity, oil saturation and oil phase mobility distributions of the HE model after 16 days of steam injection. The height of the image has been exaggerated by two times. 


\section{Conclusions}

A detailed analysis of heat transfer and fluid flow at the edge of a steam chamber translating in either vertical or horizontal directions is presented. The results show that both heat transfer by conduction and convection occurs ahead of the steam front as it propagates spatially but it is several orders of magnitude higher in the vertical translation of steam compared to the horizontal. This is due to the enhanced effect of gravity drainage that drains mobilized bitumen from the oil sand with consequent replacement of the pore volume with steam. Another result from the analysis is that heated bitumen, with its lower viscosity than cold bitumen, fingers into the cold bitumen also enhancing heat transfer rates. Reduced oil viscosity in the horizontal translation of the steam chamber does not translate to effective oil mobility because relative permeability effects lower the effective permeability of the oil phase.

Author Contributions: Conceptualization, I.D.G.; Data curation, M.A.-A.; Formal analysis, M.A.-A. and I.D.G.; Funding acquisition, I.D.G.; Investigation, M.A.-A. and I.D.G.; Methodology, M.A.-A. and I.D.G.; Visualization, M.A.-A.; Writing—original draft, M.A.-A.; Writing—review and editing, I.D.G. All authors have read and agreed to the published version of the manuscript.

Funding: The authors acknowledge financial support from Innotech Alberta, and NSERC. The authors also acknowledge support from the Canada First Research Excellence Fund program, the University of Calgary's Global Research Initiative in Low Carbon Sustainable Unconventional Resources.

Acknowledgments: The authors acknowledge Computer Modelling Group for the use of its thermal reservoir simulator, STARS ${ }^{\mathrm{TM}}$.

Conflicts of Interest: The authors declare no conflict of interest. The funders had no role in the design of the study; in the collection, analyses, or interpretation of data; in the writing of the manuscript, or in the decision to publish the results.

\section{References}

1. Gates, I.D. Basic Reservoir Engineering; Kendall Hunt Publishing Company: Dubuque, Iowa, USA, 2011.

2. Nasr, T.; Law, D.; Golbeck, H.; Korpany, G. Counter-current aspect of the SAGD process. J. Can. Pet. Technol. 2000, 39, 41-47. [CrossRef]

3. Sharma, J.; Gates, I.D. Multiphase flow at the edge of a steam chamber. Can. J. Chem. Eng. 2010, 88, 312-321. [CrossRef]

4. Sharma, J.; Gates, I.D. Convection at the edge of a steam-assisted gravity drainage steam chamber. SPE J. 2011, 16, 503-512. [CrossRef]

5. Irani, M.; Gates, I.D. Understanding the convection heat-transfer mechanism in steam-assisted gravity drainage process. SPE J. 2013, 18, 1202-1215. [CrossRef]

6. Irani, M.; Ghannadi, S. Understanding the heat-transfer mechanism in the Steam-Assisted Gravity Drainage (SAGD) process and comparing the conduction and convection flux in bitumen reservoirs. SPE J. 2013, 18, 134-145. [CrossRef]

7. Gotawala, D.R.; Gates, I.D. Steam fingering at the edge of a steam chamber in a heavy oil reservoir. Can. J. Chem. Eng. 2008, 86, 1011-1022. [CrossRef]

8. Zhu, D.; Bergerson, J.A.; Gates, I.D. On fingering of steam chambers in steam-assisted heavy oil recovery. AIChE J. 2015, 62, 1364-1381. [CrossRef]

9. Aziz, K.; Settari, A. Petroleum Reservoir Simulation; Elsevier Applied Science: London, UK, 1979.

10. Prats, M. A current appraisal of thermal recovery. J. Pet. Technol. 1978, 30, 1129-1136. [CrossRef]

11. Mehrotra, A.K.; Svrcek, W.Y. Viscosity of compressed Athabasca bitumen. Can. J. Chem. Eng. 1986, 64, 844-847. [CrossRef]

12. Phillips, A. STARS ${ }^{T M}$ User's Manual, Version 2019; Computer Modelling Group (CMG) Ltd.: Calgary, AB, Canada, 2019.

13. Good, W.K.; Rezk, C.; Felty, B.D. Possible Effect of Gas Cap on SAGD Performance; Alberta Department of Energy: Edmonton, AB, Canada, 1997.

14. Vinsome, P.; Westerveld, J. A Simple method for predicting cap and base rock heat losses in' thermal reservoir simulators. J. Can. Pet. Technol. 1980, 19, 87-90. [CrossRef] 
15. Austin-Adigio, M.; Gates, I.D. Non-condensable gas co-injection with steam for oil sands recovery. Energy 2019, 179, 736-746. [CrossRef]

16. Ito, Y.; Suzuki, S. Numerical simulation of the SAGD process in the hangingstone oil sands reservoir. J. Can. Pet. Technol. 1998, 38, 27-35.

17. Li, Q.; Chen, Z. A new analysis on the convective heat transfer at the edge of the SAGD chamber. In Proceedings of the Society of Petroleum Engineers Annual Technical Conference and Exhibition, Houston, TX, USA, 28-30 September 2015; Society of Petroleum Engineers: Richardson, TX, USA, 2015.

18. Ito, Y.; Ipek, G. Steam fingering phenomenon during SAGD process. In Proceedings of the Society of Petroleum Engineers International Thermal Operations and Heavy Oil Symposium, Calgary, AB, Canada, 1-3 November 2005; Society of Petroleum Engineers: Richardson, TX, USA, 2015.

(C) 2020 by the authors. Licensee MDPI, Basel, Switzerland. This article is an open access article distributed under the terms and conditions of the Creative Commons Attribution (CC BY) license (http://creativecommons.org/licenses/by/4.0/). 